\title{
Relationship between soil erodibility and engineering properties
}

\author{
I. Shafii, J.L. Briaud, and H.C. Chen \\ Texas A\&M University, College Station, Texas
}

A. Shidlovskaya

National Mineral Resources University, St Petersburg, Russia

\begin{abstract}
Different soils exhibit different erodibility (sand, clay) therefore erodibility is tied to soil properties. On the other hand, many researchers have attempted to develop such equations without much success. One problem is that erodibility is not a single number but a relationship between the erosion rate and the water velocity or the hydraulic shear stress. This erosion function is a curve and it is difficult to correlate a curve to soil properties. The main purpose of this study is to develop correlations between the elements of the erosion function (critical velocity, critical shear stress, slope of the erosion function) with elementary soil properties (plasticity index, mean grain size, unit weight, shear strength, and others). There are many tests to evaluate the erodibility of the soil in laboratory and in situ and to identify the erosion function (i.e. Jet Erosion Test, Erosion Function Apparatus, Hole Erosion Tests, etc.). This study deals with developing correlating equations between erodibility parameters obtained from many years of testing experience with Erosion Function Apparatus (EFA) and geotechnical properties of the soil.
\end{abstract}

\section{INTRODUCTION}

The erodibility of a soil can be defined as the relationship between the erosion rate $\dot{Z}$ and the mean depth velocity $\mathrm{v}$ of the water when it exceeds the critical velocity $v_{c}$ (Fig. 1). The following equation has been proposed:

$$
\dot{z} / v_{c}=\alpha\left(\left(v-v_{c}\right) / v_{c}\right)^{m}
$$

Where $\alpha$ and $\mathrm{m}$ are unit less coefficients depending on the properties of the soil. This definition is not perfectly satisfactory because the velocity varies in direction and intensity in the flow field. In fact, strictly speaking, the water velocity is zero at the soil-water interface. A more satisfactory definition is the relationship between the erosion rate $\dot{Z}$ and the shear stress $\tau$ at the soil-water interface when it exceeds the critical shear stress $\tau_{\mathrm{c}}$ (Fig. 1). The following equation has been proposed:

$$
\dot{z} / v_{c}=\alpha^{\prime}\left(\left(\tau-\tau_{c}\right) / \tau_{c}\right)^{m^{\prime}}
$$

Where $\alpha^{\prime}$ and $\mathrm{m}^{\prime}$ are unit less coefficients depending on the properties of the soil. The erosion function described by Eq. 2 represents the constitutive law of the soil for erosion problems much like a stress strain curve would represent the constitutive law of the soil for a settlement problem. While a shear stress based definition is an improved definition over a velocity based definition, it is still not completely satisfactory as the shear stress is not the only stress which contributes to the erosion rate. Indeed, the fluctuations in normal stress and shear stress due to turbulence intensity apply pulsations which can suck the soil particle or cluster of soil particles out of position and then entrained it in the flow through the drag force. A more complete description of the erosion function is given by Eq. 3:

$\frac{\dot{z}}{v}=\alpha\left(\frac{\tau-\tau_{c}}{\rho v^{2}}\right)^{m}+\beta\left(\frac{\Delta \tau}{\rho v^{2}}\right)^{n}+\gamma\left(\frac{\Delta \sigma}{\rho v^{2}}\right)^{p}$

Where $\dot{z}$ is the erosion rate $(\mathrm{mm} / \mathrm{hr}), v$ the water velocity $(\mathrm{m} / \mathrm{s}), \tau$ the hydraulic shear stress $\left(\mathrm{N} / \mathrm{m}^{2}\right), \tau_{\mathrm{c}}$ the threshold or critical shear stress $\left(\mathrm{N} / \mathrm{m}^{2}\right)$ below which no erosion occurs, $\rho$ the mass density of water $\left(\mathrm{kg} / \mathrm{m}^{3}\right), \Delta \tau$ the turbulent fluctuation of the hydraulic shear stress $\left(\mathrm{N} / \mathrm{m}^{2}\right)$, and $\Delta \sigma$ the turbulent fluctuation of the net uplift normal stress $\left(\mathrm{N} / \mathrm{m}^{2}\right)$. All other quantities are parameters characterizing the soil being eroded. While this model is quite thorough, it is rather impractical at this time to determine all the parameters needed in Eq. 3 on a site specific and routine basis. Today Eq. 1 and 2 are broadly accepted and will form the basis of this study.
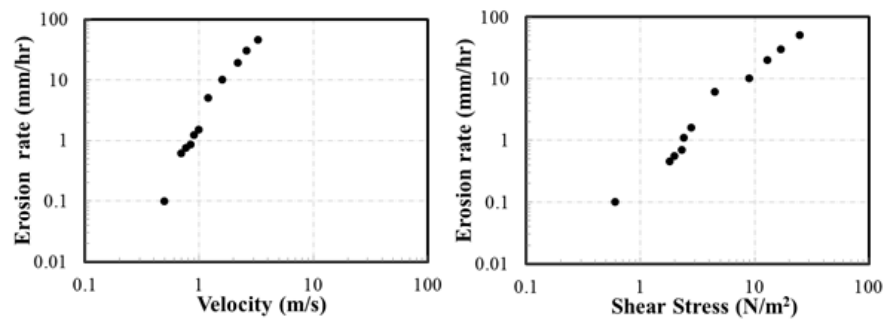

Figure 1. Examples of erosion functions (Briaud, 2013). 


\section{EXISTING SOIL EROSION TESTS}

Many soil erosion laboratory tests have been proposed over the last 25 years. Some of the more common tests are:

1. Erosion Function Apparatus (EFA) developed by Briaud in 1991 (Briaud, 2013) and similar devices developed from this initial contribution.

2. Hole Erosion Test (HET) developed by Fell (Wan and Fell, 2004).

3. Jet Erosion Test (JET) developed by Hanson (1991).

4. Rotating Cylinder Test (RCT) developed by Moore and Masch (1962).

More recently soil erosion in situ tests have been proposed including

1. Pocket Erodometer Test (PET) developed by Briaud (Briaud et al., 2012)

2. Borehole Erosion Test (BET) developed by Briaud (Briaud et al., 2016)

3. In-situ Scour Profile (ISEEP) (Gabr et al, 2013).

In all testing methods, the major erodibility parameters defined by the researchers remain the same. The first parameter is the critical velocity of the eroding fluid $v_{c}$, meaning the maximum velocity that a soil can resist without being eroded. The second parameter is the critical hydraulic shear stress at the soil surface $\tau_{c}$, meaning the maximum shear stress that the soil can resist without being eroded. The third parameter is the initial slope $E_{v}$ of the erosion rate versus velocity curve. The fourth parameter is the initial slope $E_{\tau}$ of the erosion rate vs.shear stress curve. The symbol $\mathrm{E}$ is used for these parameters because in many ways they are similar in concept to the soil modulus for deformation calculations.

\section{RELATIONSHIPS TO GEOTECHNICAL PROPERTIES}

It is well accepted that different soils have different critical velocities and different erosion rates beyond the critical threshold. Therefore soil erodibility depends on the soil properties. Many investigators have attempted to relate the erodibility of soils to basic engineering soil properties such as particle size, Atterberg limits, unit weight, water content, and shear strength. For coarse grain soils, the correlations with the mean grain size have been generally very successful because the erosion of coarse grain soils is dominated by gravity forces. For fine gran soils, other forces such as the ion-electrostatic, Van der Waals forces as well as magnetic and chemical forces become predominant and complicate the correlation significantly (after Briaud et al. 2007).
Briaud (2008) proposed a set of equations to predict the critical velocity and critical shear stress of coarse grain soils based on many erosion tests. Neil (1967) proposed an equation to predict the critical velocity of coarse grain soils based on experimental data on six sizes of graded gravels, two sizes of uniform glass balls, and cellulose acetate balls ranging in diameter from 6 to $30 \mathrm{~mm}$. For fine grained soils, Briaud (2008) bracketed the upper and lower bound. Thoman and Niezgoda (2008) based on a number of JET tests proposed a linear multiple regression equation correlating the critical shear stress and soil geotechnical properties including soil activity, dispersion ratio, specific weight, $\mathrm{pH}$ of the eroding fluid, and water content. Utley and Wynn (2008) proposed separate relationships between the critical shear stress and individual properties that they determined to be the most influential for soil erodibility. These included plasticity index, dispersion ratio, mean particle size, percent clay, and percent silt. Julian and Torres (2006) developed an equation linking the critical shear stress in $\mathrm{Pa}$ to the silt and clay content in percent. Relationships between the critical velocity/shear stress and soil properties are not easy to obtain but finding such relationships for erosion rates is even more difficult. Winterwerp and van Kesteren (2004) presented a theoretical derivation of an erosion rate parameter named M. $\mathrm{M}$ is a function of the coefficient of consolidation in the vertical direction, the volumetric concentration, the water content, the bulk and dry density, the density of water, the mean particle size, and the undrained shear strength. Hanson and Simon (2001) for soils with 50 to $80 \%$ silt size material proposed a relationship between the critical shear stress and the linear slope of the curve linking the erosion rate to the shear stress. Fig. 2 shows some of the data accumulated at Texas A\&M University for fine grain soils.

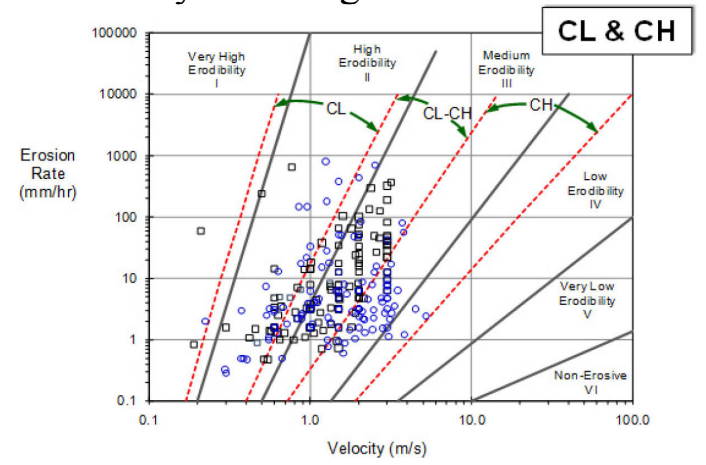

Figure 2. Example of some of Texas A\&M university soil erosion/soil properties data.

\section{EXPERIMENTAL DESIGN}

Many EFA tests have been conducted over the last 25 years at Texas A\&M University. This paper presents the results of a multiple nonlinear regression study on these EFA test results and associated ge- 
otechnical properties. The major erodibility parameters are the critical shear stress $\tau_{c}$, the critical velocity $v_{c}$, the initial slope $E_{v}$ of the $\dot{z}$ versus $v$ curve, and the initial slope $E_{\tau}$ of the $\dot{z}$ versus $\tau$ curve. In addition, the erosion function category (EC) in the Briaud erosion chart (2013) is considered as a potential parameter for the erosion correlations study. Figs. 3 and 4 show the erosion categories based on both velocity and shear stress, respectively.

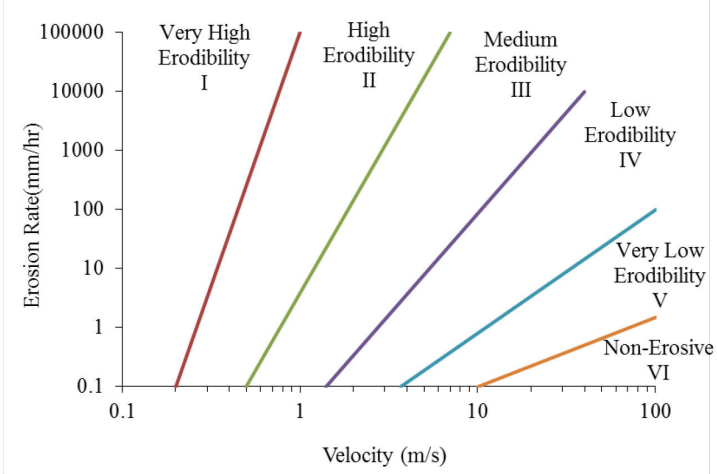

Figure 3. Erosion categories based on velocity.

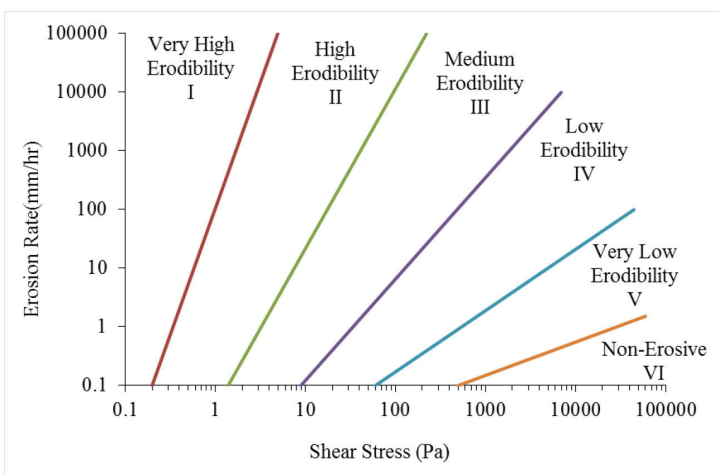

Figure 4. Erosion categories based on shear stress.

The results of more than 180 EFA tests are used. They were carried out in the erosion lab at Texas A\&M University and at the Texas Department of Transportation. All the data are analyzed according to the procedures described below for the five erodibility parameters: $\tau_{c}, v_{c}, E_{v}, E_{\tau}$, and EC.

1) Critical velocity, $v_{c}$ : All the data points of the velocity erosion curve are plotted on the erosion chart (Fig 3). If the erosion curve intercepts the horizontal axis at any point, that point is the critical velocity. Note that the horizontal axis corresponds to an arbitrarily low erosion rate of $0.1 \mathrm{~mm} /$ hour. If there is no data point on that axis, the line between the first two points of the erosion curve, is extrapolated linearly and the point at which this extrapolated line crosses the horizontal axis is selected as the critical velocity value.

2) Critical shear stress, $\tau_{c}$ : All the data points of the shear stress erosion curve are plotted on the erosion chart (Fig 4). If the erosion curve intercepts the horizontal axis at any point, that point is the critical shear stress. Note that the horizontal axis corre- sponds to an arbitrarily low erosion rate of 0.1 $\mathrm{mm} /$ hour. If there is no data point on that axis, the line between the first two points of the erosion curve, is extrapolated linearly and the point at which this extrapolated line crosses the horizontal axis is selected as the critical shear stress value. Fig. 5 shows an example of how the critical shear stress is calculated for a case where the line has to be extended to cross the horizontal axis.

3) The initial slope $E_{v}$ of the $\dot{z}$ versus $v$ plot is obtained by fitting a straight line through the early points of the curve.

4) The initial slope $E_{\tau}$ of the $\dot{z}$ versus $\tau$ plot is obtained by fitting a straight line through the early points of the curve.

5) For the erosion function category EC, the median point in the erosion curve is considered as the representative point for EC. Therefore, EC depends on the location of the median point on the erosion curve. Figure 7 shows an example of how EC is determined. EC for this particular example is obtained as 2.25 .

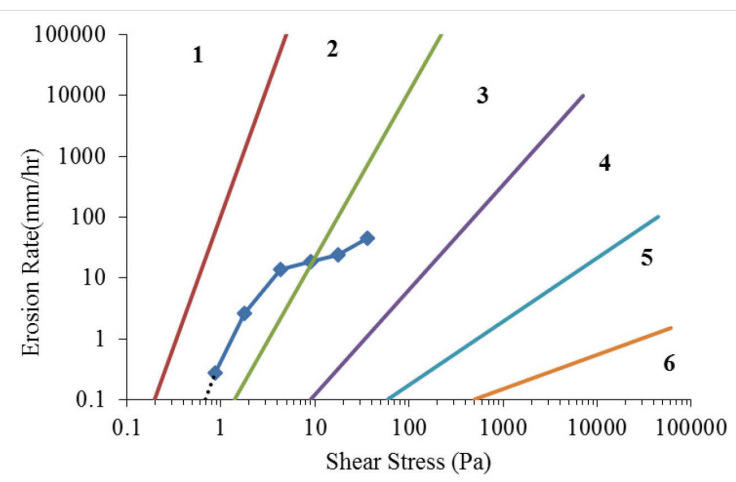

Figure 5. An example showing how critical shear stress is obtained when erosion curve itself does not cross the horizontal axis.

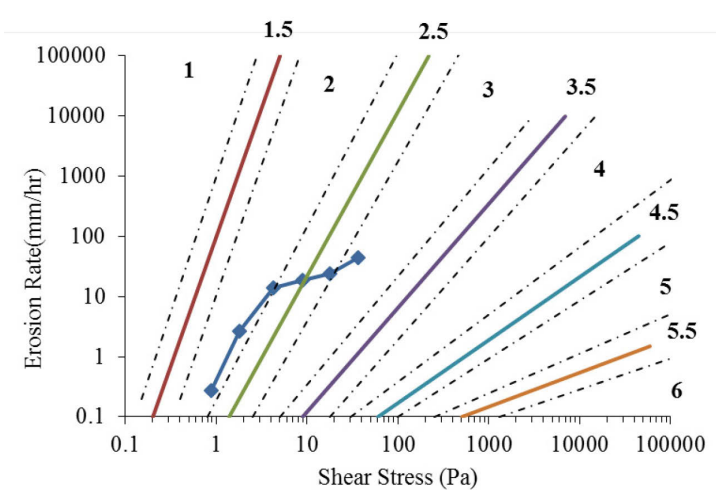

Figure 6. An example showing how EC is obtained for a sample erosion curve. 
Table 1. Regression analysis results for coarse-grain soils

\begin{tabular}{cccc}
\hline $\begin{array}{c}\text { Dependent } \\
\text { Variable }\end{array}$ & Independent Variables & Model Expression & $\mathrm{R}^{2}$ \\
\hline $\boldsymbol{\tau}_{\boldsymbol{c}}(\mathrm{Pa})$ & $\mathrm{D}_{50}(\mathrm{~mm}), \mathrm{WC}(\%), \mathrm{PF}(\%)$ & $\tau_{c}=0.165 \times\left(D_{50}{ }^{0.529}\right)\left(W C^{0.788}\right)\left(P F^{-0.23}\right)$ & 0.7 \\
$\boldsymbol{v}_{\boldsymbol{c}}(\mathrm{Pa})$ & $\mathrm{D}_{50}(\mathrm{~mm}), \mathrm{WC}(\%), \mathrm{PF}(\%)$ & $v_{c}=0.203 \times\left(D_{50}{ }^{0.185}\right)\left(W C^{0.229}\right)\left(P F^{-0.08}\right)$ & 0.4 \\
$\boldsymbol{E}_{\boldsymbol{v}}\left(\frac{\boldsymbol{m} \boldsymbol{m}}{\boldsymbol{h} \boldsymbol{r} \boldsymbol{p \boldsymbol { a }}}\right)$ & $\mathrm{D}_{50}(\mathrm{~mm}), \mathrm{WC}(\%), \mathrm{PF}(\%)$ & $E_{v}=1760 \times\left(D_{50}{ }^{-2.275}\right)\left(W C^{-4.55}\right)\left(P F^{1.7}\right)$ & 09 \\
$\boldsymbol{E}_{\boldsymbol{s}}\left(\frac{\boldsymbol{m} \boldsymbol{m}}{\boldsymbol{h} \boldsymbol{r} \boldsymbol{m} / \boldsymbol{s}}\right)$ & $\mathrm{D}_{50}(\mathrm{~mm}), \mathrm{WC}(\%), \mathrm{PF}(\%)$ & $E_{S}=55.44 \times\left(D_{50}{ }^{-4.67}\right)\left(W C^{-5.74}\right)\left(P F^{1.70}\right)$ & 0.9 \\
$\boldsymbol{E C}$ & $\mathrm{D}_{50}(\mathrm{~mm}), \mathrm{WC}(\%), \mathrm{PF}(\%)$ & $E C=1.244 \times\left(D_{50}{ }^{0.11}\right)\left(W C^{0.21}\right)\left(P F^{-0.01}\right)$ & 0.6 \\
\hline
\end{tabular}

Table 2. Regression analysis results for fine-grain soils

\begin{tabular}{|c|c|c|c|}
\hline $\begin{array}{l}\text { Dependent Var- } \\
\text { iable }\end{array}$ & $\begin{array}{l}\text { Independent } \\
\text { Variables }\end{array}$ & Model Expression & $\mathrm{R}^{2}$ \\
\hline $\boldsymbol{\tau}_{\boldsymbol{c}}(\mathrm{Pa})$ & $\begin{array}{l}\mathrm{PI}(\%), \mathrm{S}_{\mathrm{u}}(\mathrm{kPa}) \\
\mathrm{WC}(\%), \mathrm{D}_{50}(\mathrm{~mm})\end{array}$ & $\tau_{c}=0.005 \times\left(P I^{0.44}\right)\left(S_{u}^{0.83}\right)\left(W C^{1.03}\right)\left(D_{50}^{0.29}\right)$ & 0.517 \\
\hline$v_{c}(\mathrm{~Pa})$ & $\begin{array}{l}\text { PI }(\%), \mathrm{S}_{\mathrm{u}}(\mathrm{kPa}) \\
\mathrm{WC}(\%), \mathrm{D}_{50}(\mathrm{~mm})\end{array}$ & $v_{c}=0.009 \times\left(P I^{0.23}\right)\left(S_{u}^{0.49}\right)\left(W C^{0.88}\right)\left(D_{50}^{0.23}\right)$ & 0.548 \\
\hline$E_{v}\left(\frac{m m}{h r-p a}\right)$ & $\begin{array}{l}\mathrm{PI}(\%), \mathrm{S}_{\mathrm{u}}(\mathrm{kPa}) \\
\mathrm{WC}(\%), \mathrm{D}_{50}(\mathrm{~mm})\end{array}$ & $E_{v}=8.016 \times 10^{24} \times\left(P I^{-6.11}\right)\left(S_{u}^{-0.58}\right)\left(W C^{-12.55}\right)\left(D_{50}^{-1.28}\right)$ & 0.675 \\
\hline$E_{S}\left(\frac{m m}{h r-m / s}\right)$ & $\begin{array}{l}\mathrm{PI}(\%), \mathrm{S}_{\mathrm{u}}(\mathrm{kPa}) \\
\mathrm{WC}(\%), \mathrm{D}_{50}(\mathrm{~mm})\end{array}$ & $E_{S}=3.154 \times 10^{17} \times\left(P I^{-3.64}\right)\left(S_{u}^{-0.87}\right)\left(W C^{-8.65}\right)\left(D_{50}^{-1.24}\right)$ & 0.73 \\
\hline$E C$ & $\begin{array}{l}\mathrm{PI}(\%), \mathrm{S}_{\mathrm{u}}(\mathrm{kPa}) \\
\mathrm{WC}(\%), \mathrm{D}_{50}(\mathrm{~mm})\end{array}$ & $E C=1.203 \times\left(P I^{0.101}\right)\left(S_{u}^{0.114}\right)\left(W C^{0.02}\right)\left(D_{50}{ }^{0.017}\right)$ & 0.26 \\
\hline
\end{tabular}

\section{REGRESSION RESULTS}

Briaud (2008) describes erodible materials in three material categories: soil (those earth element which can be classified in USCS classification), rock (those earth elements that have an unconfined compressive strength of the intact rock core of more than 500 $\mathrm{kPa}$, with joint spacing of at least $0.1 \mathrm{~m}$ ), and intermediate geomaterials (any earth material intermediate between rock and soil). The results presented here refer to the first category: soils. Multiple nonlinear regression analysis was conducted on more than 180 EFA test results. The results of the best regression equations are summarized in Tables 1 and 2, for coarse grain soils and fine grained soils, respectively.

For coarse grain soils, in addition to effect of the mean particle size $\left(D_{50}\right)$, the effect of the water content (WC) and of the percent finer than \#200 sieve (PF) are found to be important. For fine grain soils, the effect of the undrained shear strength $\left(\mathrm{S}_{\mathrm{u}}\right)$, the plasticity index (PI), as well as the water content (WC) are added to mean particle size $\left(\mathrm{D}_{50}\right)$.

For coarse grain soils (Table 1), the mean particle size is nonlinearly proportional to the critical shear stress and critical velocity. This is in agreement with the findings of Briaud (2008) for coarse-grain soils.
The equations also show that the critical shear stress, critical velocity, and erosion category increase with an increase in water content. At the same time, the erosion slopes $E_{v}$ and $E_{\tau}$ decrease with the water content. This is consistent with an increase in critical values. It is also observed that the critical velocity and critical shear stress decrease with an increase in PF (percent passing \#200 sieve). However, the influence is relatively small. An increase in PF slightly increases the initial slope of the erosion curve, meaning that it causes a higher erosion rate. The regression equations also show that erosion function category increases with $\mathrm{D}_{50}$ and $\mathrm{WC}$, and decreases with PF, which is consistent with the results obtained for $\tau_{c}, v_{c}, E_{v}$, and $E_{\tau}$. It is also noteworthy that the $\mathrm{R}^{2}$ values are relatively high.

For fine grain soils (Table 2), it was noted earlier that $\mathrm{D}_{50}$ alone cannot properly correlate with the soil erosion resistance. Yet it adds to the goodness of fit for the multiple parameter correlation. This is attributed to the common fact that the smaller the fine grain soil particles are, the higher the plasticity which is a measure of the "stickiness" of the soil. However, the mineral composition of clay particles plays an important role as well. For example, particles represented by illite at the approximately same 
size but different physical-chemical activity would impact on the strength of the bonds between particles at different way. The undrained shear strength and the plasticity index also have an impact as they represent a measure of the strength of the bonds between particles. Table 2 shows that an increase in each of PI, $\mathrm{S}_{\mathrm{u}}, \mathrm{WC}$, and $\mathrm{D}_{50}$ of the soil lead to an increase in $v_{c}, \tau_{c}$, and EC. However similar to the results of regressions in coarse-grain soil, this decrease in the initial slopes of $E_{v}$ and $E_{\tau}$.

\section{CONCLUDING REMARKS}

The authors have performed multiple nonlinear regression analyses on more than 180 EFA tests results obtained at Texas A\&M University over the past 25 years. The regression analyses showed that involving multiple geotechnical parameters lead to increased $\mathrm{R}^{2}$ for the equations to estimate the soil erodibility parameters. The erosion function category (EC), the erosion slopes $\mathrm{E}_{\mathrm{v}}$, and $\mathrm{E}_{\tau}$ were defined and used in the regression analyses as dependent variables in addition to the critical shear stress $\left(\tau_{c}\right)$ and the critical velocity $\left(v_{c}\right)$. Two sets of equations, which link the erodibility parameters $\left(\tau_{c}, v_{c}, E_{v}, E_{s}\right.$, and EC) to geotechnical properties, are proposed for both coarse-grain soils and fine-grain soils.

It is concluded that in coarse-grain soils, an increase in $\mathrm{D}_{50}$ and WC would make the soil more resistant to erosion by increasing the critical shear stress and the critical velocity, and decreasing the initial slope of the erosion curve. For fine grain soils, it is concluded that an increase in PI, $\mathrm{S}_{\mathrm{u}}, \mathrm{WC}$, and $\mathrm{D}_{50}$ makes the soil more resistant to erosion by increasing the critical shear stress and the critical velocity, and decreasing the initial slope of erosion rate vs. shear stress/velocity curve.

This study is continuing as part of a national NCHRP project where regression analyses will be more comprehensive and extended to other test types (i.e. JET and HET). The ultimate goal of the research is to achieve the most practical and reliable common model between all types of erosion tests to estimate the erodibility parameters of a soil in the absence of erosion testing.

\section{ACKNOWLEDGEMENTS}

The authors would like to acknowledge the Texas Department of Transportation and of the Texas A\&M Transportation Institute for their contribution and sponsorship of most of this work. Many $\mathrm{PhD}$ students at Texas A\&M University have contributed over the last 25 years to perform the EFA tests thereby making this study possible.

\section{REFERENCES}

Briaud, J.-L., 2008, “Case Histories in Soil and Rock Erosion: Woodrow Wilson Bridge, Brazos River Meander, Normandy Cliffs, and New Orleans Levees", The 9th Ralph B. Peck Lecture, Journal of Geotechnical and Geoenvironmental Engineering, Vol. 134, No.10, ASCE, Reston Virginia, USA.

Briaud, J.-L., 2013, "Geotechnical Engineering: unsaturated and saturated soils", John Wiley and Sons, New York, USA.

Briaud, J.-L., Bernhardt, M., Leclair, M., 2012, "The pocket erodometer test: development and preliminary results". Geotechnical Testing Journal, Vol. 35, No. 2, Paper ID GTJ102889.

Briaud, J.-L., Chedid, M., Shidlovskaya, A., 2016, "The borehole erosion test". $8^{\text {th }}$ International Conference on Scour and Erosion. Oxford, UK.

Briaud, J.-L., Chen, H.-C., Govindasamy, A.V. and Storesund, R., 2007, "Erosion Test on Samples from the New Orleans Levees," GeoDenver 2007, Geotechnical Special Publication 161 - Embankments, Dams and Slopes, ASCE.

Gabr, M., Caruso, C., Key, A., Kayser, M., 2013, “Assessment of in situ scour profile in sand using a jet probe. Geotechnical Testing Journal, Vol. 36(2).

Hanson, G.J., 1991. "Development of a jet index to characterize erosion resistance of soils in earthen spillways", $A S A E$ Paper No. 90-2577. Vol. 34(5), pp. 2015-2020.

Hanson, G.J., and Simon, A., 2001, "Erodibility of cohesive streambeds in the loess area of the Midwestern USA", $H y$ drological Processes, 15(1): 23-38.

Julian, J.P., and Torres, R., 2006, "Hydraulic erosion of cohesive riverbanks," Geomorphology, 76 (1-2): 193-206.

Moore, W. L., Masch, F. D., Jr. 1962. "Experiments on the scour resistance of cohesive sediments". Journal of Geophysical Research, Vol. 67(4), pp. 1437-1449.

Neil, C.R. 1967, "Mean-velocity criterion for scour of coarse uniform bed-material," Proceeding of International Association for Hydraulic Research, 3:46-54.

Thoman, R. W., \& Niezgoda, S. L., 2008, "Determining erodibility, critical shear stress, and allowable discharge estimates for cohesive channels: Case study in the Powder River basin of Wyoming". Journal of hydraulic engineering, 134(12), 1677-1687.

Utley, B., \& Wynn, T., 2008, "Cohesive soil erosion: theory and practice", Paper presented at the World Environmental and Water Resources Congress.

Wan, C.F., and Fell, R., 2004, "Investigation of rate of erosion of soils in embankment dams". Journal of Geotechnical and Geoenvironmental Engineering, Vol. 130, No. 4, pp. 373380.

Winterwerp, J.C., Van Kesteren, W.G.M., 2004, "Introduction to the physics of cohesive sediment in the marine environment". Development in sedimentology series no. 56. Amsterdam: Elsevier. ISBN 0444515534. 